\title{
Does size really matter? A retrospective analysis of donor renal volume and its effects on renal function in donors after donation
}

\author{
Kheng Sit Lim*1 ${ }^{* 1}$ Suchen Tay ${ }^{1}$, Martyn Gostelow ${ }^{2}$, Stephanie MC Fook-Chong ${ }^{3}$, Lay Guat $\mathrm{Ng}^{1}$ \\ ${ }^{1}$ Department of Urology, Singapore General Hospital, Singapore \\ ${ }^{2}$ Duke-NUS Medical School, Singapore \\ ${ }^{3}$ Health Services Research, Singapore General Hospital, Singapore; Centre for Quantitative Medicine, Duke-NUS Graduate \\ Medical School, Singapore
}

Received: April 4, 2016

DOI: $10.5430 / j b g c . v 6 n 2 p 14$
Accepted: June 28, 2016

Online Published: August 16, 2016

\begin{abstract}
Introduction: It has been postulated that renal volume should play a bigger role in selection of donor kidney apart from anatomy and that the larger kidney should be kept for the donor. We attempted to investigate the correlation between donor residual renal volume and post-transplant donor renal function up to 5 years post donation.

Material and methods: Retrospective analysis was performed on all living related renal transplant at a tertiary institution from 2005-2013. Pre-operative renal volumes of donors were calculated using computer tomography (CT) images. Serum creatinine and creatinine clearance levels were collected at pre-operative, 6 months, 1 year, and 5 years post donation. Percentage residual renal volume was correlated against the percentage change in serum creatinine and creatinine clearance over the specified time points.

Results: Eighty-four donors were analyzed and the left kidney was removed in all patients. Median age was 46 years (22-76), median pre-operative renal volume was $261 \mathrm{~cm}^{3}$ (142-453) and median percentage of residual renal volume was 44\% (29-55). Median serum creatinine at pre-operative, 6 months, 1 year, and 5 years were $65,96,99$, and $91 \mu$ mol/L respectively. Median creatinine clearance at pre-operative, 6 months, 1 year and 5 years were 113, 76, 74 and $81 \mathrm{ml} / \mathrm{min}$ respectively. Serum creatinine trend showed improvement up to 5 years but creatinine clearance stabilized after 6 months. When compared against percentage residual renal volume, there were no significant correlations found with percentage change in serum creatinine and creatinine clearance over pre-operative, 6 months, 1 year or 5 years.

Discussion: There is no association between donated renal volume and changes in serum creatinine or creatinine clearance. Size of the donated kidney does not matter.
\end{abstract}

Key Words: Renal transplant, Postoperative renal function, Donor nephrectomy, Renal volum

\section{INTRODUCTION}

Renal transplantation is currently the preferred treatment for End Stage Renal Disease (ESRD) with organ transplanta- tion offering improved quality of life and survival in these patients when compared to dialysis treatment. ${ }^{[1]}$ While the utilization of Renal Replacement Therapy (RRT) has dramat-

*Correspondence: Kheng Sit Lim; Email: jay.lim@mohh.com.sg; Address: Singapore General Hospital, 1 Outram Road, Singapore. 
ically increased the survival of these patients, this number can only be expected to increase as the prevalence of ESRD continues to rise from diabetes and hypertension.

Advances in surgical technique and development of better immunotherapy resulted in increased graft survival rate over the past few decades. Including advances that allow for ABO incompatible transplantation, renal transplantation has been increasingly accepted as a viable treatment modality. ${ }^{[2]}$

Potential donors are rigorously screened to assess suitability in high volume renal transplantation centers. Several studies have shown that the long-term outcome after donor nephrectomy remains comparable with the general population. ${ }^{[3-5]}$ There is also evidence to suggest that a larger donated renal volume confers a better outcome in the recipients and is an independent determinant of post transplant graft outcomes. ${ }^{[6-8]}$ The impact of residual renal volume on donor renal function is less clear.

The selection of donor kidney in our tertiary institution currently focuses on kidney anatomy with the following considerations: 1) renal vasculature; 2) length of the vessels; and 3) absence of abnormal renal anatomy. With no formal measurement of the relative size of each kidney, the above three criteria take precedence to the relative size of each kidney. In the light of this historical practice, we aim to retrospectively investigate the correlation between the remaining kidney volume of the donor and the post transplant donor renal serum creatinine $(\mathrm{Cr})$ and Creatinine Clearance $(\mathrm{CCr})$ at 6 months, 1 year, and 5 years as well as the correlation between removed kidney volume and $\mathrm{Cr}$ and $\mathrm{CCr}$ levels. ${ }^{[1]}$

\section{MATERial AND Methods}

We performed an institutional review board approved retrospective analysis of all living kidney donors performed at our institution between January 2005 and December 2013. As per our institution's protocol, a computerized tomography (CT) abdomen and pelvis with contrast was obtained for each potential renal donor to assess vascular anatomy since 2005 . With the existing CT scans, we retrospectively calculated the respective kidney volumes of the donors. Each CT scan sequence included a minimum of coronal and transverse images for which length was obtained from the coronal view $(\mathrm{mm})$, and width and thickness $(\mathrm{mm})$ were obtained from the transverse sequence. We used the ellipsoid method to estimate the kidney volume from the measurements obtained. (Kidney volume $=$ length $\times$ width $\times$ thickness $\times(\pi / 6)$ ).

Two independent investigators read each patient's CT scan to obtain the length, width and thickness of both left and right kidneys. To minimize inter observer variability, we defined the length of the kidney as measured from the tip of the up-

Published by Sciedu Press per pole to the lower pole and the width of the kidney as the thickest measurement at the level of the hilum encompassing the hilum on the coronal scans. The thickness of each kidney was defined as the thickest transverse measurement from the anterior to the posterior aspect of the kidney at the level of the renal hilum using the transverse scan.

The two sets of measured kidney volumes from the 2 raters were averaged to obtain the volumes for both left and right kidneys after ascertaining that inter-rater variability was negligible. In the absent of abhorrent vascular anatomy the left kidney was harvested as per the institution's practice. A percentage residual renal volume was calculated for each patient as follow:

$$
\begin{aligned}
& \% \text { Residual Renal Volume }=\frac{\text { Residual Kidney Volume }}{\text { Total Kidney Volume }} \\
& \times 100 \%
\end{aligned}
$$

Post operatively these patients are also followed up life long by the Transplant Clinic of the institution. At each visit, $\mathrm{Cr}$ level and 24 hours urine volume were measured to monitor renal function. Cr level and $\mathrm{CCr}$ pre operatively, at around 6 months, 1 year, and 5 years post donation were collected as part of our study. CCr was calculated using the formula;

$$
\begin{aligned}
& \text { Creatinine clearance }=\frac{\text { Creatinine }_{\text {urine }}}{\text { Creatinine }_{\text {serum }}} \\
& \times \frac{\text { Volume }_{\text {urine }}(\mathrm{ml})}{\text { Time }(\min ) \times 1440}
\end{aligned}
$$

Statistical analyses were performed using IBM SPSS Statistics version 21. Statistical significance was assumed at $p$ $<.05$. Continuous variables were summarized as median (range) and categorical variables as numbers (\%). End-points of $\mathrm{Cr}$ and $\mathrm{CCr}$ were measured at baseline, 6 months, 1 year, and 5 years. The difference in $\mathrm{Cr}$ and $\mathrm{CCr}$ at each time point and against pre op baseline was performed and the changes were analysed by Wilcoxon Signed Rank test for statistical significance. Correlation of $\mathrm{Cr}$ and $\mathrm{CCr}$ changes against percentage volume were tested by Pearson correlation statistics at 6 months, 1 year, and 5 years.

\section{Results}

A total of 84 donors who underwent donor nephrectomy between January 2005 and December 2013 were included. All patients were noted to have donated their left kidney during this period of time. Baseline characteristic of this group are shown in Table 1. Median transplant age was 46 years (22- 
76). Median kidney volume was $261 \mathrm{~cm}^{3}$ (142-453), median pre donation $\mathrm{Cr}$ was $65 \mu \mathrm{mol} / \mathrm{L}$ (44-118) and median pre donation CCr $113 \mathrm{ml} / \mathrm{min}$ (54-209). The mean percentage residual renal volume was $44 \%$ (29-55) suggesting that the left kidney is commonly the larger of the two kidneys and was donated unintentionally.

Table 1. Demographics $(\mathrm{n}=84)$

\begin{tabular}{|ll|}
\hline Sex: $\mathrm{n}(\%)$ & $\begin{array}{l}\text { male: } 35(41.6), \\
\text { female: } 49(58.3)\end{array}$ \\
$\begin{array}{l}\text { Median donation age, years (range) } \\
\text { Median total renal volume, } \mathrm{cm}^{3} \text { (range) }\end{array}$ & $261(142-76)$ \\
$\begin{array}{l}\text { Median pre op Serum Creatinine, } \mu \mathrm{mol} / \mathrm{L} \\
\text { (range) }\end{array}$ & $65(44-118)$ \\
$\begin{array}{l}\text { Median pre op Serum Creatinine Clearance, } \\
\text { ml/min (range) }\end{array}$ & $113(54-209)$ \\
$\begin{array}{l}\text { Median percent of residual renal volume, } \% \\
\text { (range) }\end{array}$ & $44(29-55)$ \\
Number of donated left kidney $(\%)$ & $84(100)$ \\
\hline
\end{tabular}

The estimated total kidney volumes obtained from the 2 independent raters were well correlated, as can be appreciated by the high value of intra-class correlation (ICC) of 0.989 (95\% CI: $0.975-0.995)$.

\subsection{Serum creatinine}

Of the 84 donors, 5 years, 1 year, 6 months and pre-operative Cr clearance were available for $36(42 \%)$ patients, $66(79 \%)$ patients, 81 (96\%) patients and 84 patients (100\%) respectively. As expected there was a statistically significant in- crease in $\mathrm{Cr}$ from pre-operation baseline to 6 months post donation ( $\mathrm{n}=81$, change from baseline, median: $33 \mu \mathrm{mol} / \mathrm{L}$, $p<.001)$. Cr subsequently decreased thereafter at 1 year and at 5 years post donation compared with the baseline (see Figure 1).

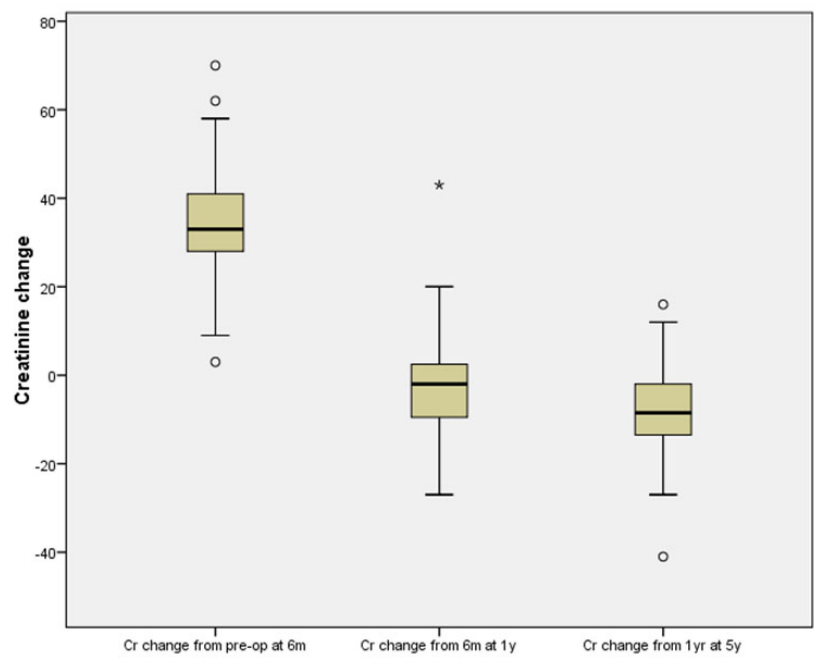

Figure 1. Boxplot of $\mathrm{Cr}$ change $(\mu \mathrm{mol} / \mathrm{L})$ at each time point from the previous time point measurement

Comparing Cr between 6 months and 1 year post donation, there was an improvement in Cr levels $(\mathrm{n}=63$, median change $-2 \mu \mathrm{mol} / \mathrm{L}, p=.017$ ). At 5 years, $\mathrm{Cr}$ continued to improve compared with 1 year after donation $(\mathrm{N}=36$, median change: $-9 \mu \mathrm{mol} / \mathrm{L}, p<.001$ ) (see Table 2 ).

Table 2. Serum creatinine post donation

\begin{tabular}{|c|c|c|c|c|}
\hline Timing post donation & Pre op & 6 months & 1 year & 5 year \\
\hline n (\%) & $84(100)$ & $81(96)$ & $66(79)$ & $36(42)$ \\
\hline Median Creatinine, $\mu \mathrm{mol} / \mathrm{L}$ (range) & $65(44-118)$ & $96(59-158)$ & $99(60-146)$ & $91(54-127)$ \\
\hline \multicolumn{5}{|c|}{ Change in serum creatinine, umol/L; median ( $p$ value $)$} \\
\hline Difference (6 months - Pre op), $\mathrm{n}=81$ & $33(p<.001)$ & & & \\
\hline Difference ( 1 year -6 months $\&), n=63$ & & $-2(p<.017)$ & & \\
\hline Difference ( 5 year -1 year), $n=36$ & & & $-9(p<.001)$ & \\
\hline
\end{tabular}

\subsection{Serum creatinine clearance}

Of the 84 donors, 5 years, 1 year, 6 months and pre-operative CCr were available for $32(38 \%)$ patients, 66 patients (79\%), 79 patients (94\%) and 84 patients (100\%) respectively. While there were significant decrease in $\mathrm{CCr}$ (see Figure 2) in the pre and 6 months period $(\mathrm{n}=78$, median change $-38 \mathrm{ml} / \mathrm{min}$, $p<.001)$, CCr stabilized after the initial 6 months. At 1 year, there is no significant change in $\mathrm{CCr}$ from 6 months $(\mathrm{n}=62$, median change $-2 \mathrm{ml} / \mathrm{min}, p=.514)$. At 5 years, there is no significant change in $\mathrm{Cr}$ clearance from 1 year $(\mathrm{n}=32$, median change $13 \mathrm{ml} / \mathrm{min}, p=.058$ ) (see Table 3 ).

Correlation analyses were performed looking at the percentage change in $\mathrm{Cr}$ and $\mathrm{CCr}$ against percentage kidney volume donated. There were no significant correlation between the percentage of donated kidney volume versus percentage change in Cr from baseline at 6 months, 1 year, and 5 years ( $p>.05$ for all, see Table 4). The percentage change in $\mathrm{CCr}$ from baseline at 6 months, 1 year, and 5 years was also not correlated with the percentage kidney volume donated $(p>$ .05 for all, see Table 5). 
Table 3. Serum creatinine clearance post donation

\begin{tabular}{|c|c|c|c|c|}
\hline Timing post donation & Pre op & 6 months & 1 year & 5 year \\
\hline $\mathrm{n}(\%)$ & $84(100)$ & $79(94)$ & $66(79)$ & $32(38)$ \\
\hline Median Creatinine Clearance $\mathrm{ml} / \mathrm{min}$ (range) & $113(54-209)$ & $76(20-206)$ & $74(24-167)$ & $81(43-153)$ \\
\hline \multicolumn{5}{|c|}{ Change in serum creatinine clearance, $\mu \mathrm{mol} / \mathrm{L} ;$ median ( $p$ value) } \\
\hline Difference (6 months - Pre op), $\mathrm{n}=78$ & $-38(<.001)$ & & & \\
\hline Difference ( 1 year -6 months), $\mathrm{n}=62$ & & $-2(.514)$ & & \\
\hline Difference ( 5 year -1 year $), n=32$ & & & $13(.058)$ & \\
\hline
\end{tabular}

Table 4. Correlation analysis of \% Donated Renal Volume vs \% Cr change

\begin{tabular}{llll}
\hline \% Renal volume donated & $\begin{array}{l}\text { \% Cr Change from pre op to } \\
\mathbf{6} \text { months }\end{array}$ & $\begin{array}{l}\text { \% Cr Change from pre op } \\
\text { to 1 year }\end{array}$ & $\begin{array}{l}\text { \% Cr Change from pre op to } 5 \\
\text { years }\end{array}$ \\
\hline Pearson correlation, $\mathrm{r}$ & 0.074 & 0.040 & 0.248 \\
$p$-value & .512 & .749 & .146 \\
$\mathrm{~N}$ & 81 & 66 & 36 \\
\hline
\end{tabular}

Table 5. Correlation analysis of \% Donated Renal Volume vs. \% CCr change

\begin{tabular}{llll}
\hline \% Renal volume donated & $\begin{array}{l}\text { \%CCr Change from pre op } \\
\text { to } \mathbf{6} \text { months }\end{array}$ & $\begin{array}{l}\text { \% CCr Change from pre } \\
\text { op to 1 year }\end{array}$ & $\begin{array}{l}\text { \% CCr Change from pre op to } \\
\mathbf{5} \text { years }\end{array}$ \\
\hline Pearson correlation, $\mathrm{r}$ & -0.088 & -0.048 & -0.197 \\
$p$-value & .444 & .704 & .289 \\
$\mathrm{~N}$ & 78 & 65 & 31 \\
\hline
\end{tabular}

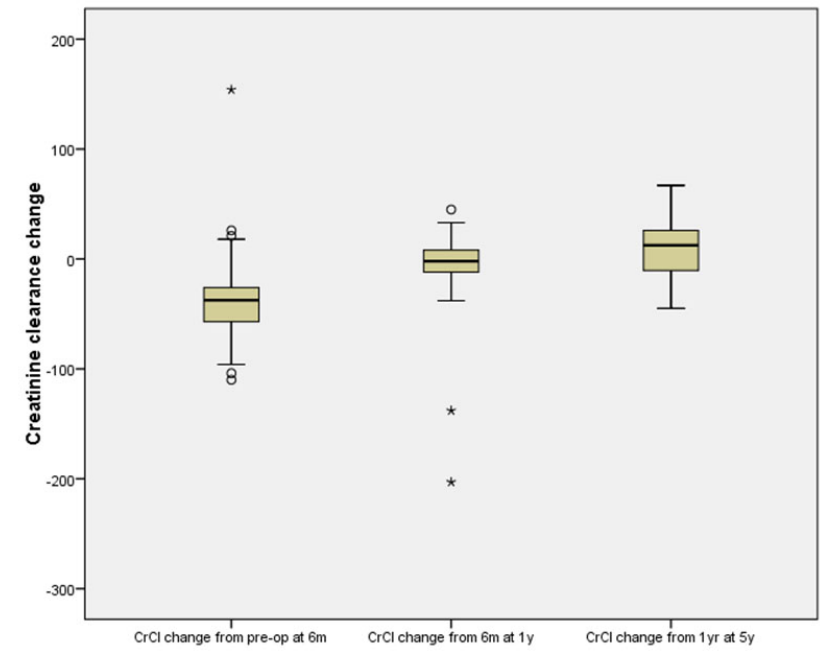

Figure 2. Boxplot of $\mathrm{CCr}$ change at each time point from the previous time point measurement

\subsection{Subgroup analysis}

One possible confounding factor in our study was the large variation between donors at the extreme ends. While we note that the larger kidney were donated with a mean percentage residual renal volume of $44 \%$, there was nearly 2 fold difference (29\%-55\%) in term of residual renal volume. There was also a 3-fold difference between the small and the largest donated volume (median volume was $261 \mathrm{~cm}^{3}$, range Published by Sciedu Press
$142 \mathrm{~cm}^{3}-453 \mathrm{~cm}^{3}$ ) with resultant percentage difference in $\mathrm{Cr}$ and $\mathrm{CCr}$. The age group similar varied over a large range from 22 years to 76 years. This raises the possibility of "averaging" any meaningful differences that might exist in the extreme ends of the data range.

A separate analysis was performed that divided percentage residual renal volume range in thirds $(\leq 42 \%, 43 \%-46 \%$, $\geq 47 \%$ ) and their corresponding changes in percentage change $\mathrm{Cr}$ and $\mathrm{CCr}$ examined. Similarly, an analysis by age into two groups was performed and examined.

\subsubsection{Residual renal volume}

$\mathrm{Cr}$ change and $\mathrm{CCr}$ change at each time point from the previous time (e.g. $6 \mathrm{mths}$ - pre, $1 \mathrm{yr}-6 \mathrm{mths}$ ) followed the same trend for each subgroup as compared to the whole group anaylsis (see Figures $3 \& 4$ ). Cr changes and $\mathrm{CCr}$ changes did not differ significantly between the 3 tertiles $(n=27,29$, 28 ) of percentage residual renal volume ( $p>.05$ for all).

\subsubsection{Age}

The patients were separated into two age groups using the median age of 46 years. $\mathrm{Cr}$ change and $\mathrm{CCr}$ change at each time point from the previous time (e.g. $6 \mathrm{mths}$ - pre, 1yr-6 mths) followed the same trend for each age subgroup as for whole group (see Figures 5 \& 6). Cr changes and $\mathrm{CCr}$ changes were found to not be significant between the 3 tertiles of $\%$ residual renal volume ( $p>.05$ for all). 

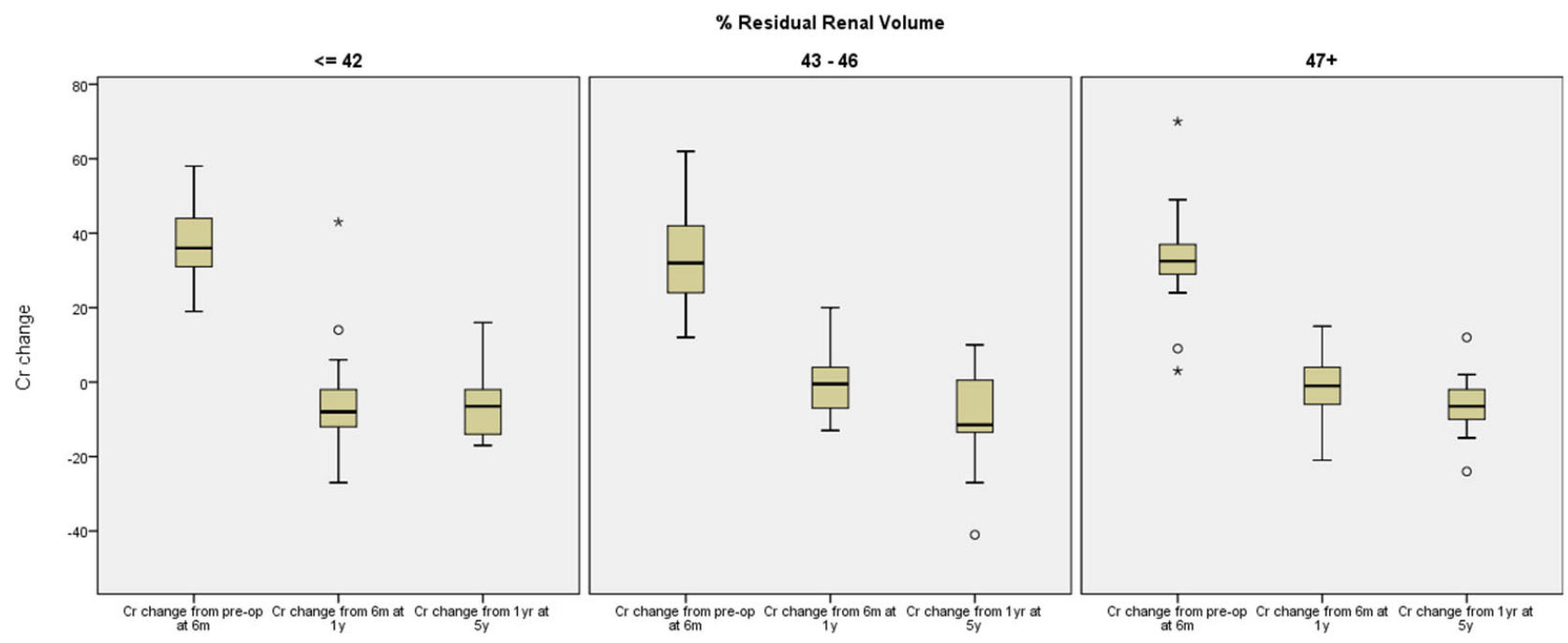

Figure 3. Boxplot of $\mathrm{Cr}$ change $(\mu \mathrm{mol} / \mathrm{L})$ at each time point from the previous time point measurement for 3 tertile subgroups of $\%$ residual renal volume

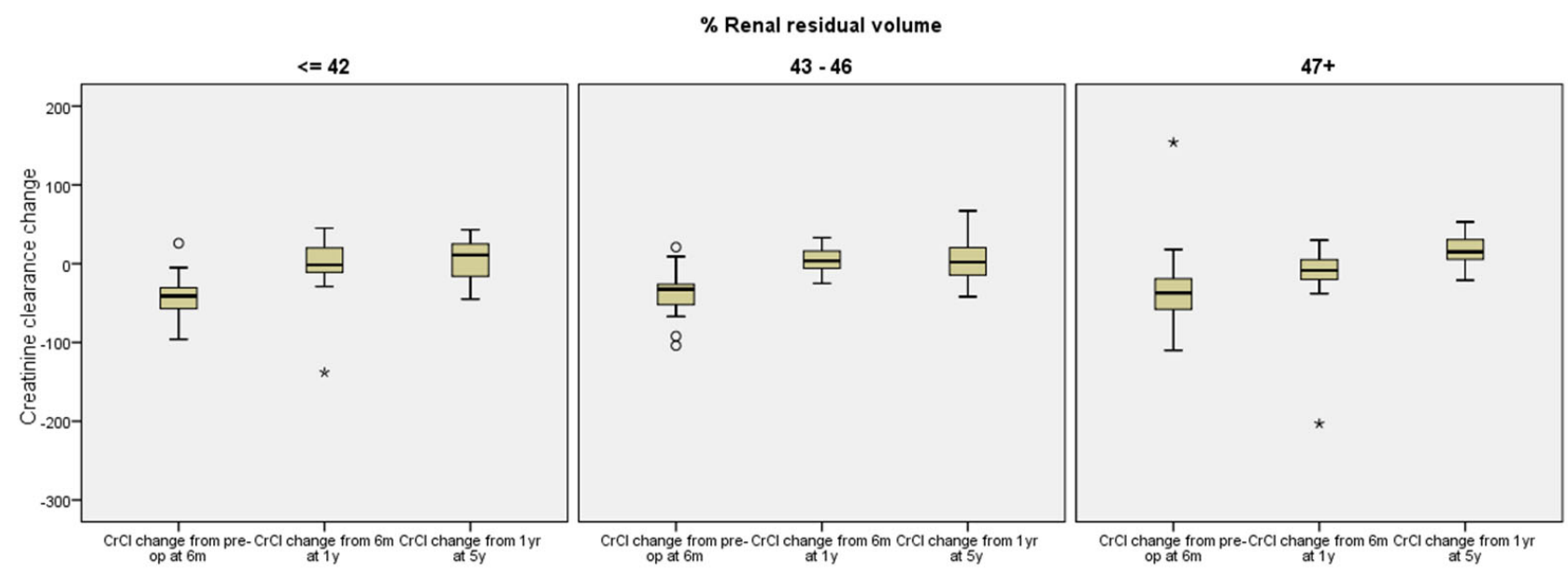

Figure 4. Boxplot of $\mathrm{CCr}$ change $(\mathrm{ml} / \mathrm{min})$ at each time point from the previous time point measurement for 3 tertile subgroups of $\%$ residual renal volume

Figure 5. Boxplot of $\mathrm{Cr}$ change $(\mu \mathrm{mol} / \mathrm{L})$ at each time point from the previous time point measurement for 2 subgroups of age

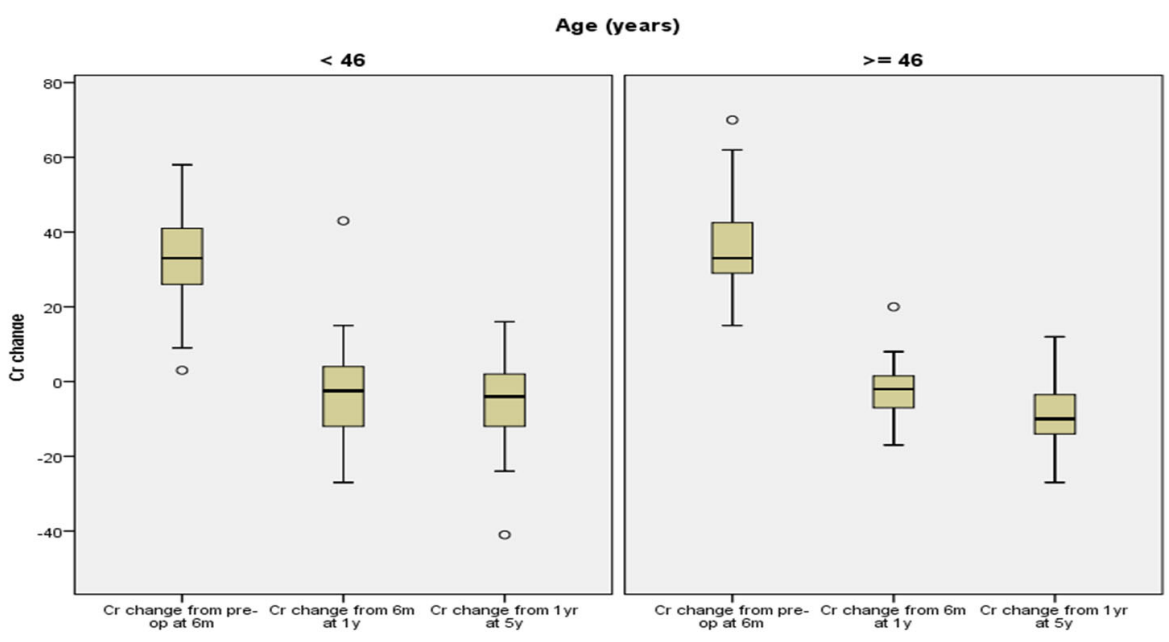




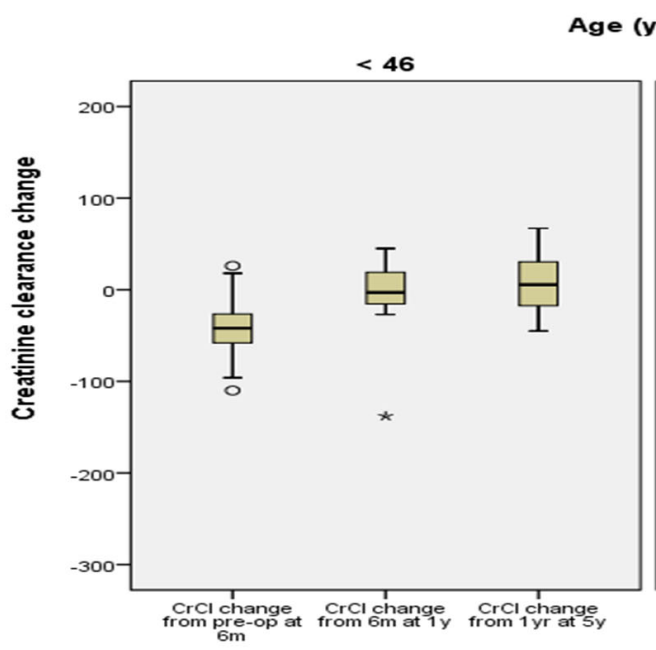

\section{DISCUSSION}

As the prevalence of end stage renal disease increases internationally, the number of living kidney donor transplantations have increased $50 \%$ over the last decade. ${ }^{[9]}$ Together with the medical advancements in developing protocols for $\mathrm{ABO}$ incompatible transplants, the pool of potential kidney donors have increased for each recipient. As the motives are altruistic, this elective loss of an otherwise normally functioning organ demands detailed information and post-donation outcomes to be clearly made known to potential donors. Donor registries have been set up in many countries to monitor the long-term health and welfare of kidney donors. This is necessary as it is ethically important to ensure that donors' health are not being overly compromised post-transplant.

Prior studies have shown that larger donated kidney volume lowers the incidence of acute cellular rejection and results in better-estimated glomerular filtration rate (eGFR) at two years post-transplant in the recipient. ${ }^{[7,10]}$ These findings, together with dual cadaveric renal transplants, form the belief that "more is better" for the recipient. However, this introduced the ethical dilemma that leaving the smaller kidney for the donor could potentially compromise the residual renal function.

Renal donors have longer longevity than their counterparts, with the rationale being that kidney donors are heavily screened and thus are healthier pre-operatively than individuals in their age cohort. ${ }^{[11]}$ However, recent studies with greater enrollment numbers and more robust follow-up data have shown that there is no statistically significant difference in long-term risk of death between live donors and an age- and comorbidity-matched cohort. The same study also showed the rate of surgical mortality for kidney donors has remained stable at 3.1 per 10,000 despite advances and changes in donor selection. ${ }^{[12]}$ As such, kidney donors face a morbidity from an immediate risk peri-operatively but not from the long term risk of inadequate renal function.

\subsection{Serum markers}

Our aim was to examine the correlation between donor residual volume and post-transplant donor renal function 5 years post-operatively. While eGFR has been accepted as a more robust estimation of renal function, we used creatinine-based approximation of GFR as these biomarkers were readily collected from our donors on follow up, and allows for direct comparison over long follow up periods. The CockcroftGault equation would be a better estimation of renal function and may provide valuable insights into correlations relationship between renal volume and function, which is something to consider for future studies.

Both $\mathrm{Cr}$ and $\mathrm{CCr}$ changed significantly from baseline to 6 months. Renal function as measured by $\mathrm{Cr}$ improved thereafter at 1 year (change in CR: $-2 \mu \mathrm{mol} / \mathrm{L}, p<.017$ ) and continued to improve up to 5 years $(-9 \mu \mathrm{mol} / 1, p<.001)$ after donation. CCr continued to decrease till the 1 year point although at a slower rate (difference ( $1 \mathrm{yr}-6 \mathrm{mths}$ ): $-2 \mathrm{ml} / \mathrm{min}$ ). At the 5 years mark, CCr improved by $13 \mathrm{ml} / \mathrm{min}$ from the 1 year mark $(p=.058$ ), which was close to statistical significance. This shows that renal deterioration does not persist after donation but instead stabilizes for the first few years and may even show trends of improvement beyond 5 years.

We believe the reversal in renal function that can be seen in serum $\mathrm{Cr}$ and $\mathrm{CCr}$ (although not statistically significant) is a result of renal hypertrophy as a means of homeostasis to support the physiological need of the body. We believe that the trend of $\mathrm{CCr}$ follows that of creatinine but it is less clear as to the duration of deterioration and the turning point when renal function starts to improve. Our finding is also similar to Fehrman-Ekholm et al., whose cross-sectional retrospective study on the living kidney donors and their renal function 
demonstrated that renal function continues to improve for up to 8 years but will show some signs of slight deterioration in the longer run. ${ }^{[13]}$

\subsection{Correlation relationships}

When comparing the percentage change in renal volume versus serum $\mathrm{Cr}$ and $\mathrm{CCr}$, we found no strong relationship exists. The residual renal volume for the donor does not affect the change in serum markers. This we believe is due to hypertrophy as a result of homeostasis. It is a dynamic process to achieve equilibrium and not for the purpose of nephron replacement. Contrary to our results, Hugen et al. have shown that donated kidney volume correlated with donor $\mathrm{Cr}$. This may be due to a more sensitive modality used in volume calculation and the use of body surface area in renal function assessment that were not available in our cohort. ${ }^{[14]}$ While the relatively small number may compound the results of the correlation studies especially at the 5 years follow up, we believe this relationship is a true representation of the dynamics between renal volume and serum markers.

We further divided our data set into smaller subgroup despite our small sample size to investigate for significant correlation relationship. Compensatory hypertrophy as a result of homeostasis is also likely to be inversely proportional to age. This avoids over simplification and averaging of the results. While the results were similar to the whole group analysis, we believe it is important to explore subgroup correlation to account for the large difference in the terms of residual renal and age and their corresponding renal function changes.

Our center routinely selects the left kidney due to ease of surgery and renal vessel length. Incidentally in our study, the transplanted left kidney was on average larger than the right kidney, resulting in the donor having a mean residual renal volume of $43.6 \%$ (28.8-54.5). We argue that the robustness of our correlation relationship is boosted by this unintended selection. Moreover, we noted that at the very least $\mathrm{CCr}$ plateaus at 1 year post donation and may continue to improve up to 5 years post donation.

\section{Conclusion}

Based on these findings, we conclude that the size of the kidney is not a crucial determinant in the welfare of the kidney donor as long as safety considerations are not compromised. As previous research has suggested that a larger kidney size benefits the recipient, it is ethically acceptable to transplant either kidney, even if this results in the selected kidney being the slightly larger of the two. Muzzale et al. wrote that although there is an increased risk of ESRD in renal donors, the magnitude of absolute risk increase was very small, thus supporting our conclusion as well. ${ }^{[15]}$ Future directions for this clinically and ethically important question would be with three dimensional radiological measurement of pre and post-operative renal volume and the usage of GFR with age, ethnicity and BMI factored in to investigate the relationship between residual renal volume and renal function in the renal donor. We eagerly await future research on this topic for validation of our findings.

\section{CONFLICTS OF INTEREST DisClOSURE}

The authors declare that they have no conflicts of interest.

\section{REFERENCES}

[1] Davis CL, Delmonico FL. Living-Donor Kidney Transplantation: A Review of the Current Practices for the Live Donor. Journal of the American Society of Nephrology. July 1, 2005; 16(7): 2098-2110. PMid: 15930096. http://dx.doi.org/10.1681/ASN. 2004100 824

[2] Mok IY, Kee T, Goh A. Ten-year Outcomes of Kidney Transplants at the Singapore General Hospital. Proceedings of Singapore Healthcare Volume. 2012; 21(2).

[3] Najarian JS, McHugh LE, Matas AJ, et al. 20 years or more of follow-up of living kidney donors. The Lancet. 10/3/1992; 340(8823): 807-810.

[4] Hakim RM, Goldszer RC, Brenner BM. Hypertension and proteinuria: long-term sequelae of uninephrectomy in humans. Kidney international. Jun 1984; 25(6): 930-936. PMid: 6381857. http://dx.doi.org/10.1038/ki.1984.112

[5] Goldfarb DA, Matin SF, Braun WE, et al. RENAL OUTCOME 25 YEARS AFTER DONOR NEPHRECTOMY. The Journal of Urology. 12/2001; 166(6): 2043-2047.
[6] Giral M, Nguyen JM, Karam G, et al. Impact of Graft Mass on the Clinical Outcome of Kidney Transplants. Journal of the American Society of Nephrology. January 1, 2005; 16(1): 261-268. PMid: 15563571. http://dx.doi.org/10.1681/ASN. 2004030209

[7] Poggio ED, Hila S, Stephany B, et al. Donor kidney volume and outcomes following live donor kidney transplantation. American journal of transplantation: official journal of the American Society of Transplantation and the American Society of Transplant Surgeons. Mar 2006; 6(3): 616-624.

[8] Saxena AB, Busque S, Arjane P, et al. Preoperative renal volumes as a predictor of graft function in living donor transplantation. American Journal of Kidney Diseases. 11/2004; 44(5): 877-885.

[9] Horvat LD, Shariff SZ, Garg AX. Global trends in the rates of living kidney donation. Kidney international. 2009; 75(10): 1088-1098. PMid: 19225540. http://dx.doi.org/10.1038/ki.2009. 20

[10] El-Agroudy AE. Is living-donor kidney volume an independent determinant of post-transplantation graft performance? Nature Clinical Practice Nephrology. 2006; 2(10): 556-557. PMid: 17003832. http://dx.doi.org/10.1038/ncpneph0288 
[11] Fehrman-Ekholm I, Elinder CG, Stenbeck M, et al. KIDNEY DONORS LIVE LONGER1. Transplantation. 1997; 64(7): 976-978. PMid: 9381544. http://dx.doi.org/10.1097/00007890-199 710150-00007

[12] Segev DL, Muzaale AD, Caffo BS, et al. Perioperative mortality and long-term survival following live kidney donation. Jama. 2010; 303(10): 959-966. PMid: 20215610. http://dx.doi.org/10.10 01/jama.2010.237

[13] Fehrman-Ekholm I, Kvarnström N, Söfteland JM, et al. Postnephrectomy development of renal function in living kidney donors: a cross-sectional retrospective study. Nephrology Dialysis Transplan- tation. March 31, 2011. http://dx.doi.org/10.1093/ndt/gfr 161

[14] Hugen CM, Polcari AJ, Farooq AV, et al. Size does matter: donor renal volume predicts recipient function following live donor renal transplantation. The Journal of Urology. 2011; 185(2): 605-609. PMid: 21168871. http://dx.doi.org/10.1016/j.juro. 2010 .09 .098

[15] Muzaale AD, Massie AB, Wang MC, et al. Risk of end-stage renal disease following live kidney donation. Jama. 2014; 311(6): 579-586. PMid: 24519297. http://dx.doi.org/10.1001/jama.2013.2 85141 